\title{
Simulation and Optimization of Aviation Integral Impeller Machining Based on VERICUT
}

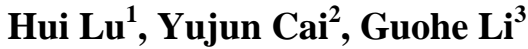 \\ ${ }^{1,2,3}$ Tianjin Key Lab of High Speed Cutting and Precision Machining, Tianjin University of Technology and Education No.1310,Dagu South \\ Road, Hexi District, Tianjin 300222, China
}

\begin{abstract}
Aviation integral impeller is a typical complex high-precision parts, impeller's blade channel spacing is small. Leaf distortion is large and complex geometric structure which caused great difficulties for processing. In this paper, the DMU60 five axis machine tool is used to process the aviation integral impeller. The geometric simulation model of NC machining is built in the VERICUT software. It can effectively check the collision between the tool and fixture, the spindle and the working table, etc. In addition, the numerical control program is optimized by VERICUT optimization module, which can improve the machining efficiency and reduce the wear of machine tool and tool.
\end{abstract}

Keywords: aviation integral impeller, VERICUT CNC simulation, feed rate, optimization

\section{Introduction}

Aviation integral impeller is a typical complex high-precision parts, impeller's blade channel spacing is small ${ }^{[1]}$. Leaf distortion is large and complex geometric structure which caused great difficulties for processing. The processing methods, machining precision and surface quality of the aviation integral impeller have the direct influence of the impeller performance. These factors have a decisive impact on the performance of the engine. During the machining process of aviation integral impeller, the tool axis changes frequently, so it is easy to interference or over-cutting phenomenon ${ }^{[2]}$. With the rotation of the spindle or the worktable, if the consideration is not comprehensive, the spindle and the worktable or fixture is easy to collide. For the five axis high-speed machining, cutting parameter selection is not suitable for cutting tool breakage and parts cutting phenomenon. The selection of cutting parameters has not yet been guided by a perfect method theory, and it often depends on the experience of the process personnel in actual production. In view of the above problems, the relevant scholars have done a lot of research based on VERICUT software ${ }^{[3-5]}$.

The American CGTEC company's VERICUT is the most representative geometry simulation software. Its main function is to complete the numerical simulation of the $\mathrm{NC}$ program, tool interference checking and the optimization of the $\mathrm{NC}$ code $^{[6]}$. VERICUT can be connected with the mainstream CAM software in the world, mainly to solve the problem of model conversion, NC program transmission and so on, and improve the efficiency of the process simulation. With the application of numerical control technology in the practical production, VERICUT software has been widely used. At present, many foreign companies such as Canada's Bombardier, Germany's Volkswagen, American Boeing company applied the VERICUT software to the production practice. In the country there are Qingdao Haier Limited by Share Ltd, Tianjin automobile die Limited by Share Ltd, Shenyang aircraft manufacturing company using VERICUT ${ }^{[7]}$. In this paper, according to the DMG company's DMU60 five axis machine tool machining of aviation integral impeller, based on VERICUT software for NC machining geometry simulation and optimization of cutting speed.

\section{Establish VERICUT simulation environment}

The establishment of the NC machining simulation platform mainly includes the establishment of the model of machine tool, setting the parameters of the machine tool, the configuration of the control system of the machine tool and the establishment of the tool magazine. DMG company's DMU60 is table-rotating five-axis machine, and its control system is Heidenhain iTNC530. The machine as shown in Figure 1. X, $\mathrm{Y}, \mathrm{Z}$ axis is a linear motion axis, $\mathrm{B}, \mathrm{C}$ axis is the axis of rotation. The linear axis travel limits of the machine: $\mathrm{Y}, \mathrm{X}, \mathrm{Z}$ linear axis are $630 \mathrm{~mm}, 560 \mathrm{~mm}, 560 \mathrm{~mm}$, B-axis of rotation range is $-120^{\circ} \sim 30^{\circ}$, and $\mathrm{C}$-axis of rotation range is $-360^{\circ} \sim 360^{\circ}$.

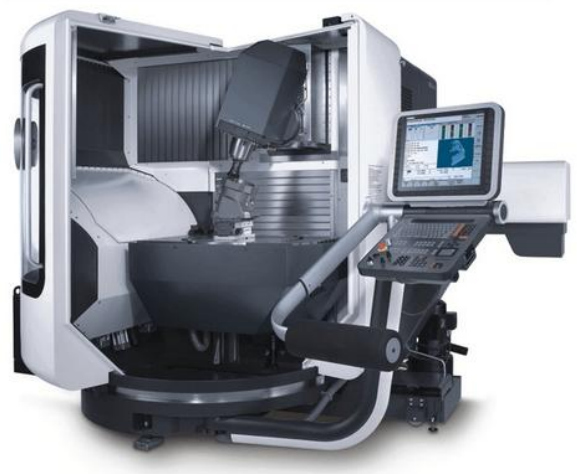

Figure 1: DMU60 machine

Firstly, the geometric model of the machine tool is established by measuring the actual machine tool in CAD software. Secondly, the establishment of the machine tool project tree, imported machine geometry model, set up the machine parameters to complete the establishment of simulation model of the machine in VERICUT . At last, adding the control file which is consistent with the NC system of the machine tool, creating the necessary fixture and tool model for machining the integral impeller, setting the offset of the G-code, 


\section{International Journal of Science and Research (IJSR) \\ ISSN (Online): 2319-7064}

Index Copernicus Value (2013): 6.14 | Impact Factor (2014): 5.611

completing the DMU60 numerical control simulation machine tool as shown in Figure 2.

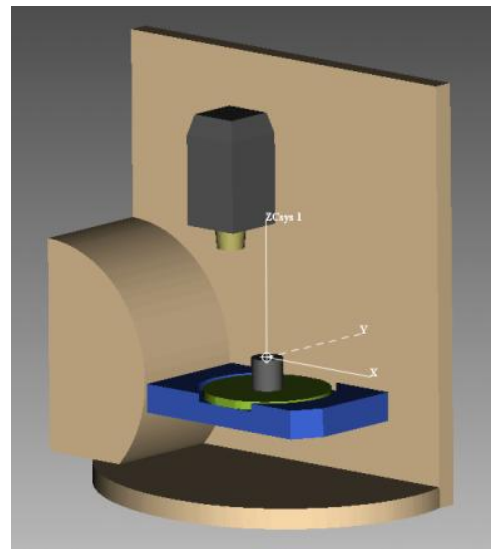

Figure 2: DMU60 simulation machine tool

The successful establishment of DMU60 CNC machine tool simulation is key aviation integral impeller machining simulation and optimization. In the process of building a machine model in VERICUT, the following points need to be paid attention to: First, the coordinate value of the motion axis in the machine tool project tree is the position coordinates in the machine coordinate system in the state of motion axis homing; Second, the geometric model of the machine tool is created in the CAD software, the coordinate system of the geometric model must be consistent with the machine tool coordinate system in VERICUT; Third, G-Code Offsets Branch need to consider the structure of the machine when it is set. Different machine tool structures correspond to different G-Code Offsets Branch.

\section{Machining Simulation of the Aviation Integral Impeller}

The model of the impeller stock and the impeller parts are added in the DMU60 NC simulation tools. In order to simulate the machining process of the aviation integral impeller, the coordinate system is established, and the NC program of the impeller is introduced. The simulation of the aviation integral impeller is shown in Figure 3. The movement of the machine tool is clearly observed through the VERICUT simulation. It can determine whether there is interference between the cutter and the fixture or the spindle and the working table. After the end of the simulation, the detailed information of the machining process is obtained by viewing the VERICUT log, AUTO-DIFF Report file.

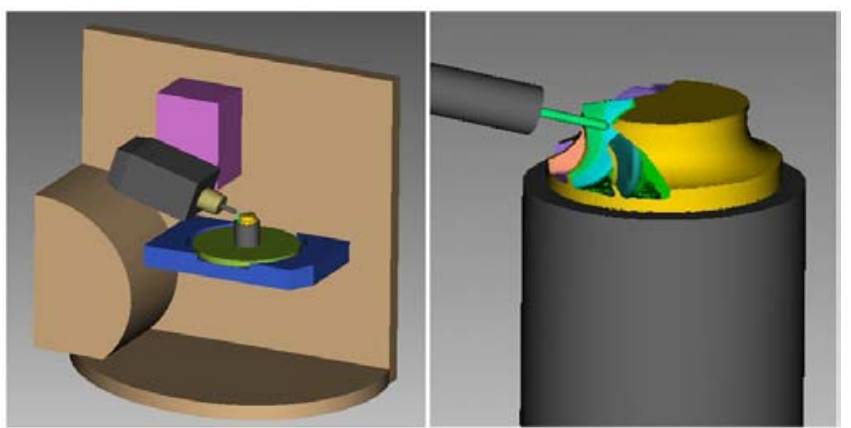

Figure 3: Impeller machining simulation process

\section{Cutting speed VERICUT \\ optimization based \\ on}

VERICUT has automated and user-selectable optimization that can maximize the material removal process. VERICUT has two kinds of optimization methods, such as constant volume removal rate and constant cutting thickness. The principle of constant volume removal is to adjust the feed rate by setting a cutting volume $(\mathrm{Vol})$. Vol $=($ ap $\times$ ae $\times F) \div 60$, Where ap is the cutting depth, ae is the cutting width, and $F$ is the feed rate. When the cutting volume is zero, the cutting tool has no cutting work piece, so that the cutting speed can be improved. When the cutting volume is larger than the value of the optimized library, the cutting speed is reduced. When the cutting volume is smaller than the value of the optimized library, the cutting speed is increased. The optimization principle of constant cutting thickness is to maintain a constant cutting thickness by changing the feed rate. This method is mainly used for finishing.

The method of constant volume removal is used to optimize the cutting speed of the rough machining of the aviation integral impeller. The VERICUT optimization library is built on the tool library. Each tool can be created different optimization library based on different cutting material, cutting conditions, the use of machine tools in the tool library. Open processing tool dialog box, select the roughing tool to add a new optimization. Axial depth of cut is set to $0.691 \mathrm{~mm}$, the radial depth of cut is set to $3 \mathrm{~mm}$, volume removal is set to $5182 \mathrm{~mm}^{3} / \mathrm{min}$, spindle speed is set to $7980 \mathrm{r} / \mathrm{min}$. Then the optimization library is set up as shown in Figure 4.

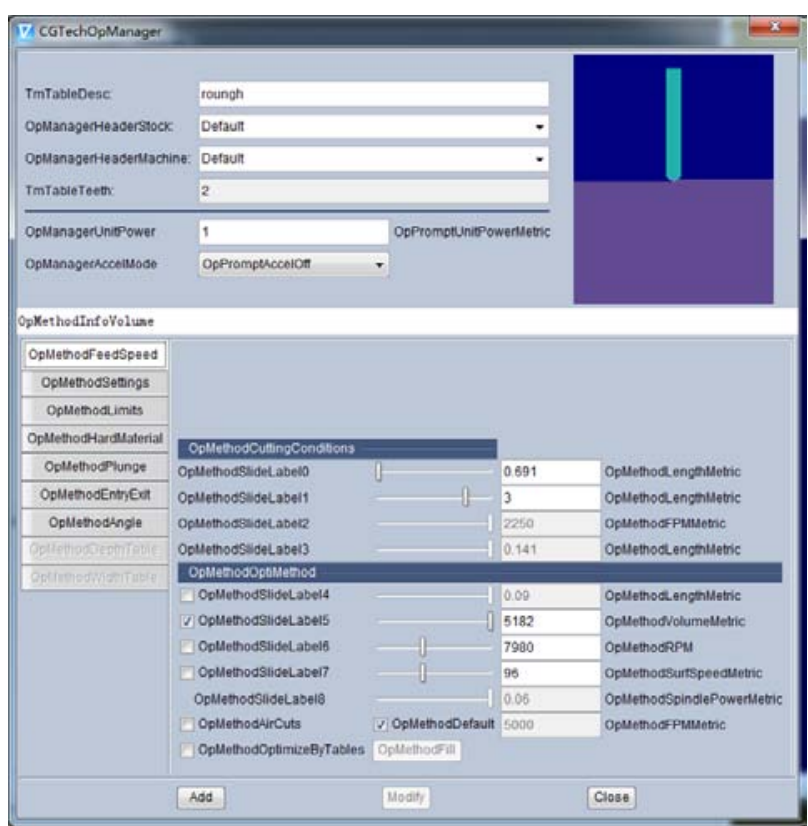

Figure 4: Optimization parameter setting

The rough machining process of the aviation integral impeller is optimized, and the optimization results are shown in Figure 5 . The rough machining time of the integral impeller can be saved by $22.49 \%$ as shown in the red box in Figure 5. 


\section{International Journal of Science and Research (IJSR)}

ISSN (Online): 2319-7064

Index Copernicus Value (2013): 6.14 | Impact Factor (2014): 5.611

OptiPathCalculator
\begin{tabular}{|l|l|}
\hline OPCalcPartSavings \\
\hline OPCalcorigTime & $0: 14$ \\
OPCalcOptiTime & $0: 11$ \\
\hline OPCalcPercentrime & 22.49 \\
\hline OPCalcNumParts 100 \\
OPCalcMachRate 100 \\
OPCalcTimeSaved \\
OPCalcMoneySaved \\
OPCalculatePartsSavings \\
\hline
\end{tabular}

Figure 5 Optimization Results

Original NC program and optimized NC programs were compared as shown in Figure 6. The left side is the optimized $\mathrm{NC}$ programs, the right is original NC program. Figure 6 shows that VERICUT optimization does not change the tool path of the original program, only to adjust the feed rate of NC program according to the cutting volume. The red program code in Figure 6 is the feed rate that is inserted according to the cutting volume.

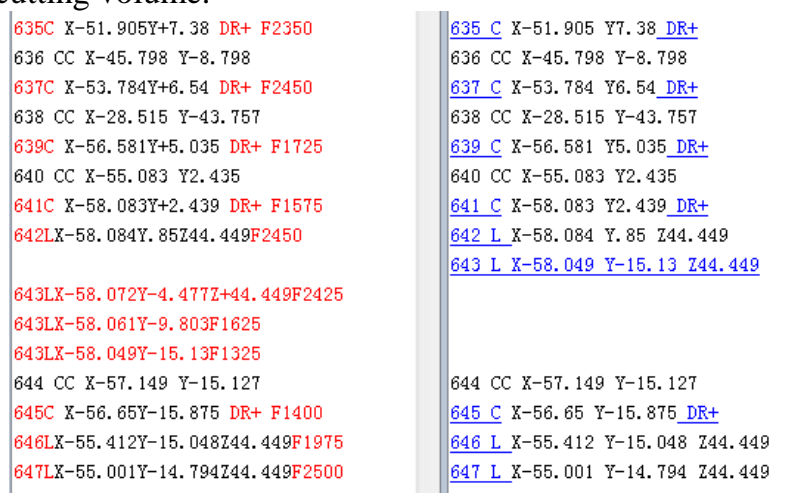

Figure 6 Compare NC Program Files

\section{Experimental Verification}

The original NC program and the optimized NC program are used for the rough machining of the aviation integral impeller in order to verify the result of the VERICUT optimization. The experimental results show that the optimized program is shorter than the cutting time of the original program by $22.49 \%$, which is consistent with the VERICUT optimization results. The aviation integral impeller is processed as shown in Figure 7 . The left blade is obtained by using the original NC program, the right blade is the optimized NC program. Figure 7 shows that the left blade have over-cutting phenomenon, the right blade did not. The reason is that the feed rate of the original program is constant, the tool does not slow down in the corner cutting. That led to over-cutting. The optimized NC program according to the actual amount of cutting to adjust the feed rate, at the corner to reduce the cutting speed, so there is no over-cutting.

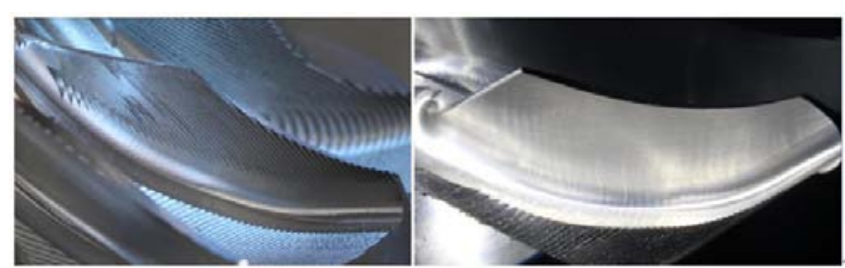

Figure 7: The finished blade

\section{Conclusion}

The simulation and optimization of VERICUT can effectively check the interference and improve the processing efficiency in the process of the aviation integral impeller. A simulation model of NC machining of the aviation integral impeller is built in the VERICUT software which can effectively check the collision between the tool and the fixture, the spindle and the working platform of the whole machining process. In addition, the NC program is optimized by VERICUT optimization module. So the machining efficiency of parts is improved. The wear of machine tools and tools is reduced. The content of this paper can provide reference for other impeller processing, and it has certain engineering significance.

\section{Acknowledgement}

This work is supported by Tianjin Universities" Training Plan of Subject leading Personnel"(RC14-02) and college-level project of Tianjin University of Technology and Education (KJY1306) and Tianjin Science and Technology Support Project(13ZCZDGX01108) and Subject of Science and Technology Development Fund of Tianjin college (20130408);

\section{References}

[1] Young H T, Chuang L C, Gerschwiler K.A five-axis rough machining approach for a centrifugal impeller $[\mathrm{J}$ ] .Int J Adv Manuf Technic, 2004, 23:233-239

[2] Koichi Morishige\&Yoshimi Takeuchi. 5-Axis control rough cutting of an impeller with efficienby and accuracy [J]. International Coferency on Robotics and Automation, 1997:1241-1246

[3] QIN Lu-fang, SUN Tao, SHI Si-qiang, YANG Lu. Research of CNC Machining Simulation for Integral Impeller Based on Software UG [J]. Modular Machine Tool \& Automatic Manufacturing Technique, 2015:98-102.

[4] NA Ming-chen , LIANG Peng. Research and optimization of the cutting tool parameter relations based on VERICUT [J]. Journal of Shenyang Aerospace University,2012(6):34-38.

[5] TANG Qing-chun, LIU Qian, MA Zhong-liang, ZHANG Jian. The Application Research of VE R ICUT Simulation Software in Five Axis Machining [J]. Modular Machine Tool \& Automatic Manufacturing Technique,2014(9):131-135.

[6] ZHAO Li-zhong, GUO Deng-yue, MA Yun-hui, YAN Ji-hong. Establishment and Teaching Application of NC Simulation Environment Based on VERICUT [J]. RESEARCH AND EXPLORATION IN LABORATORY, 2013(1):24-27.

\section{Volume 4 Issue 11, November 2015}




\section{International Journal of Science and Research (IJSR) \\ ISSN (Online): 2319-7064}

Index Copernicus Value (2013): 6.14 | Impact Factor (2014): 5.611

[7] Huang Yunlin, Zheng Zhenping. VERICUT7.3 Chinese version of $\mathrm{NC}$ simulation technology and detailed examples $[\mathrm{M}]$. Beijing: Mechanical Industry Press,2015.1.

\section{Author Profile}

Lu hui is reading the M.S. degrees in Mechanical Engineering from

Tianjin University of Technology and Education. 